\title{
ANALISIS DAMPAK KEBIJAKAN TARIF PROGRESIF DALA M HUBUNGAN DWELLING TIME DAN YARD OCCUPANCY RATIO (YOR) DI TERMINAL PETIKEMAS SEMARANG
}

\author{
Harji Sunanda ${ }^{1}$, Henita Rahmayanti ${ }^{2}$ \\ Email: harjisunanda21@gmail.com ${ }^{1}$, henita.rahmayanti@unj.ac.id ${ }^{2}$ \\ 1 \\ Prodi D III Transportasi, Fakultas Teknik - Universitas Negeri Jakarta \\ Prodi D III Transportasi, Fakultas Teknik - Universitas Negeri Jakarta
}

\begin{abstract}
Abstrak. Menganalisis dampak kebijakan tarif progresif terhadap dwelling time dan YOR. Kelancaran suatu terminal petikemas dipengaruhi rendah nya dwelling time dan YOR. Untuk mencapai target $d w e l l i n g$ time kurang dari 3 hari dan YOR dibaawah 50\% ditetapkan kebijakan tarif progresif. Diberlakukannya tarif progresif diharapkan dapat menurunkan dwelling time dan YOR di semua terminal petimekas agar mampu mencapai target yang diharapkan pemerintah serta guna mendapatkan efisiensi serta kelancaran arus petikemas. Diberlakukannya tarif progresif diharapkan dapat menurunkan dwelling time dan YOR di semua terminal petimekas agar mampu mencapai target yang diharapkan pemerintah serta guna mendapatkan efisiensi serta kelancaran arus petikemas. Data sekunder yang berupa data dwelling time dan YOR pada tahun 2016-2018. Data yang didapatkan tersebut kemudian dianalisis menggunakan korelasi pearson guna mengatahui hubungan antara dwelling time dan YOR dan kemudian data dwelling time dan YOR akan dibuat grafik guna mengetahui sebelum kebijakan tarif progresif dan sesudah kebijakan tarif progresif dan dianalisis agar mendapatkan solusi dari permasalahan melancarkan arus petikemas di terminal petikemas. Hasil dari analisis data didapatkan bahwa dampak kebijakan tarif progresif belum bisa menurunkan dwelling time dan YOR secara signifikan, dan masih sangat tinggi nya angka dwelling time dan YOR di Terminal Petikemas Semarang setelah tarif progresif rata-rata 6,14 hari sedangkan untuk YOR rata-rata setalh tarif progresif mencapai nilai $63,51 \%$ sehingga berdampak mahal nya biaya logistik.
\end{abstract}

Kata kunci: Tarif progresif, Dwelling Time, YOR

\begin{abstract}
Abstrac, This final project was conducted during an internship at Terminal Petikemas Semarang which is a company in the field of packaging terminal services. This study aims to analyze the impact of tariff progressive policies on dwelling time and YOR. To achieve the target of dwelling time in less than 3 days and YOR under $50 \%$ a progressive tariff policy is set. . the implementation of progressive tariffs is expected to reduce dawling time and YOR, in all of container terminal to be able achieve target expected by the government and to obtain efficiency and smoothly flow of container. To compile this final project the author uses secondary data in the form of dwelling time and YOR data in 2016-2018.

Data obtained then it was analyzed using pearson correlation to know the rapport between dwelling time and YOR then, data dwelling time and YOR will be graphed to find out before progressive tariff policies in analysis in order to get a solution to the problems that exist in order to facilitate the flow of containers in the container terminal. The results of data analysis found that the impact of progressive tariff policies not yetcan reduce dwelling time and YOR significantly and still very much the high of dwelling time and YOR at the Semarang Container Terminal after the progressive rate reached $63.51 \%$ and dwelling time 6.14 days then progressive tariffs will not affect dwelling time and YOR.
\end{abstract}

Keyword: Progressive Tarif, Dwelling Time, Yard occupancy ratio

\section{A. PENDAhuluan}

Perdagangan internasional saat ini mengalami perkembangan yang cukup pesat sarana angkutan penunjang untuk mengirim barang antar negara juga meningkat, dengan begitu pertumbuhan arus barang mengalami pola pergerakan dari yang tadinya konvensional menjadi lebih modern yaitu menggunakan petikemas. Pengiriman barang menggunakan petikemas semakin banyak diminati karena faktor keamanan dan lebih praktis, penggunaan petikemas untuk sarana pengangkutan di bidang jasa transportasi laut terus berkembang secara pesat di seluruh negara salah satunya Indonesia. Guna tercapainya efisiensi dan efektivitas pengiriman barang menggunakan petikemas maka di perlukan bantuan dari sub pendukung lain yaitu teriminal petikemas sebagai fasilitas penunjang utama.

Terminal petikemas merupakan salah satu fasilitas penunjang yang ada di pelabuhan guna melakukan kegiatan bongkar muat barang. Pihak terminal petikemas harus memiliki tanggung jawab dan memberikan 
pelayanan yang baik guna memberikan kenyamanan dan kepuasan kepada pengguna jasa. Maka, sudah seharusnya terminal petikemas mampu mengelola semua sumber daya yang dimiliki agar menghasilkan kinerja yang optimal dan mampu bersaing dengan terminal petikemas lainnya.

Pelabuhan Tanjung Emas merupakan pelabuhan yang berkembang kearah pelabuhan yang besar dan modern. Pelabuhan Tanjung Emas memiliki terminal petikemas yang salah satunya adalah terminal petikemas semarang (TPKS). TPKS yaitu terminal yang bergerak dibidang jasa bongkar muat petikemas yang melayani jasa kegiatan pembongkaran, penumpukan, pemuatan, dan behandle.

TPKS merupakan terminal petikemas yang cukup modern karena hampir semua kegiatannya menggunakan sistem, sehingga terminal petikemas ini menarik untuk diteliti terutama mengenai kecukupan lapangan penumpukannya dalam melayani pengguna jasanya. Untuk mengukur kinerja sebuah terminal petikemas biasanya diukur dari kinerja operasionalnya atau kinerja selama bongkar muatnya dan lama nya petikemas berada di lapangan penumpukan. Penunjang kegiatan bongkar muat membutuhkan fasilitas lapangan penumpukan yang memadai sebagai lokasi penumpukan sementara petikemas sebelum petikemas diambil oleh pemilik barang ataupun petikemas dimuat ke kapal.

Topik yang diangkat dalam tugas akhir ini ialah mengenai dampak kebijakan tarif progresif petikemas impor terhadap dwelling time dan YOR di TPKS. Dalam hal ini akan membahas lapangan penumpukan terhadap berapa lamanya dwelling time di TPKS. Dwelling time mengacu pada lamanya waktu inap petikemas di pelabuhan setelah petikemas turun dari kapal.

Adapun kondisi faktual yang terjadi mengenai dwelling time di TPKS 2018 nilai rata-rata masih diatas 5 hari dan YOR masih diatas 50\%.

\section{B. METODE PENELITIAN}

Penelitian ini dilakukan pendekatan secara analisis kualitatif, melalui analisis kualitatif mengandung makna suatu penggambaran atas data dengan menggunakan kata dan baris kalimat. Penelitian ini menggunakan pendekatan kualitatif, yang bertujuan memahami suatu situasi sosial, peristiwa, peran, interaksi dan kelompok. Data dan informasi yang digunakan dalam penelitian ini didapat dari data operasional perusahaan dan wawancara. Informasi yang didapat dari data sekunder perusahaaan, cacatan wawancara, dan foto kegiatan. Informasi tersebut dalam bentuk dokumen dan catatan peristiwa yang diolah menjadi data.

Data sekunder adalah data yang diperoleh peneliti dari sumber yang sudah ada dalam arsip (data dokumen) dari Terminal Petikemas Semarang, data ini di dapatkan selama menjalankan Program Magang.

a. Data Perbandingan dan pencapaian petikemas Tahun 2016 -2018 oleh TPKS.

b. Data capacity CY. Laporan ini berisi jumlah setiap kapasitas di lapangan penumpukan.

\section{HASIL DAN PEMBAHASAN}

Berdasarkan data yang diperoleh dari hasil wawancara dan data yang di peroleh dari staff TPKS, Operasional, dan pihak terkait yang ada di TPKS. Proses kegiatan Bongkar muat sering terhambat hal ini yang akan membuat lapangan penumpukan di TPKS terkadang overload dan membuat dwelling time dan yor akan meningkat.

\section{Dwelling Time di TPKS Sebelum Kebijakan Tarif Progresif 2016}

Dwelling time adalah lamanya waktu inap petikemas sejak petikemas dibongkar sampai petikemas meninggalkan terminal petikemas. Rendahnya rata-rata dwelling time petikemas TPKS dapat mengukur penghematan biaya agar optimalnya arus petikemas di TPKS dan sedikit pengurangan dwelling time bisa membuat dampak yang signifikan terhadap kapasitas penumpukan atau CY. Nilai dwelling time selama satu tahun di TPKS tahun 2016 sebelum kebijakan tarif progresif di angka 6,25 hari. 


\section{Dwelling Time (Hari)}

6

4

2

0

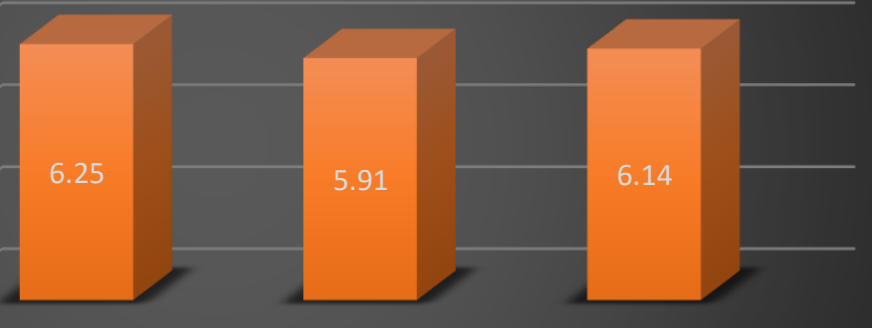

$20162017 \quad 2018$

Gambar 1 Dwelling Time Sebelum Tarif Progresif Tahun 2016-2018

2. Yard Occupancy Ratio Impor (YOR) Sebelum Kebijakan Tarif Progresif

Yard Occupancy Ratio (YOR) ialah perbandingan kapasitas lapangan. Banyaknya petikemas di lapangan penumpukan berarti penggunaan lapangan penumpukan semakin mendekati kapasitas maksimal penumpukan di lapangan penumpukan. Untuk meperlancar arus petikemas dan pelayanan di TPKS harus memperhatikan keseimbangan YOR di lapangan penumpukan agar arus petikemas dapat berjalan sesuai dengan jadwal yang telah ditetapkan.

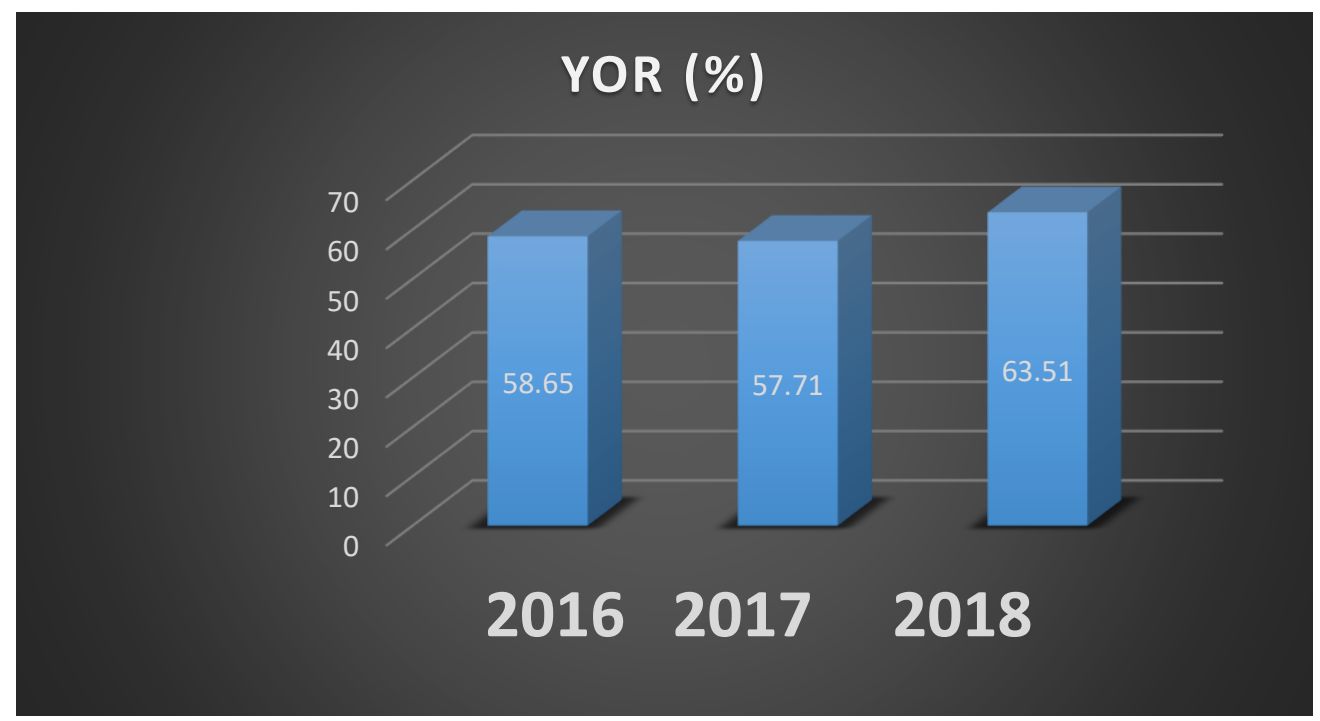

Gambar 2 YOR Sebelum Tarif Progresif Tahun 2016-2018 
Tabel 1 YOR Impor dan Throughput TPKS 2016-2018

\begin{tabular}{|c|c|c|}
\hline $\mathbf{2 0 1 6}$ & $\mathbf{2 0 1 7}$ & $\mathbf{2 0 1 8}$ \\
\hline 301.298 TEUs & 310.269 TEUs & 329.114 TEUs \\
\hline
\end{tabular}

Pada tabel 1 terlihat bahwa rata-rata YOR TPKS setiap tahun nya kenaikan dan penurunan yang artinya tidak konsisten YOR di TPKS.

3. Hubungan Antara Dwelling Time Dan Yard Occupancy Ratio

Tabel 2 Hasil Uji Pearson Correlation

\begin{tabular}{ccc}
\hline Variabel & $\mathbf{r}$ & $\rho($ rho $)$ \\
\hline Dwelling Time & 0.749 & 0.000 \\
\hline
\end{tabular}

Berdasarkan tabel 2 hasil uji pearson correlation terdapat hubungan yang bermakna yaitu dwelling time dan yor berhubungan dengan Tarif Progresif di peroleh nilai $\rho 0,000$ dengan nilai $r=0,749$ yang artinya mempunyai hubungan atau korelasi positif sangat kuat. Semakin tinggi Dwelling Time dan YOR maka tarif akan di naikan.

4. Dampak Tarif Progresif kepada Dwelling Time

Dwelling Time dan YOR di TPKS pada tahun 2016 sebelum kebijakan tarif progresif dan sesudah tarif progresif tahun 2018 mengalami kenaikan dan penurunan. Namun, dwelling time rata-rata setelah kebijakan tarif progresif masih berada di kisaran 5,65 hari di tahun 2018.

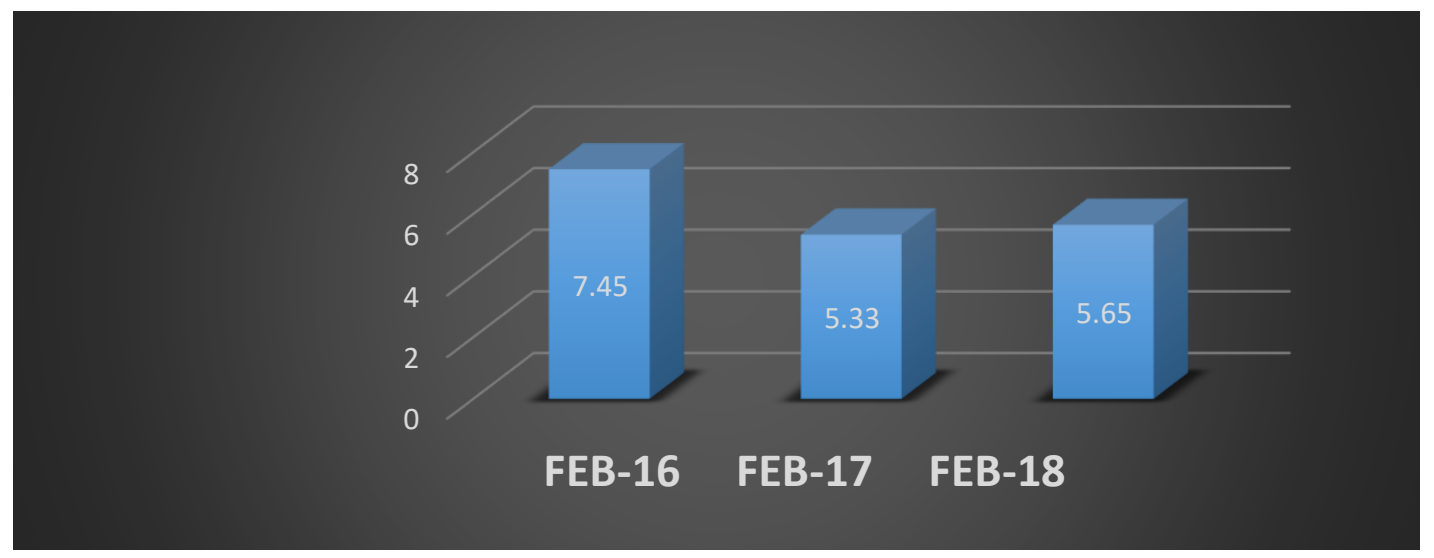

Gambar 4 Perbandingan Dwelling Time Impor Setelah Tarif Progresif

5. Dampak Tarif Progresif Kepada Yard Occupancy Ratio (YOR) 
Begitu pun dengan YOR, rata-rata YOR TPKS masih belum mampu di bawah 50\% dengan rata-rata YOR setelah kebijakan tarif progresif sebesar 56\% di tahun 2018 sehingga dalam hal ini kebijakan tarif progresif masih belum tepat dalam menurunkan dwelling time dan yor di lapangan penumpukan TPKS seperti pada gambar 3.4 berikut:

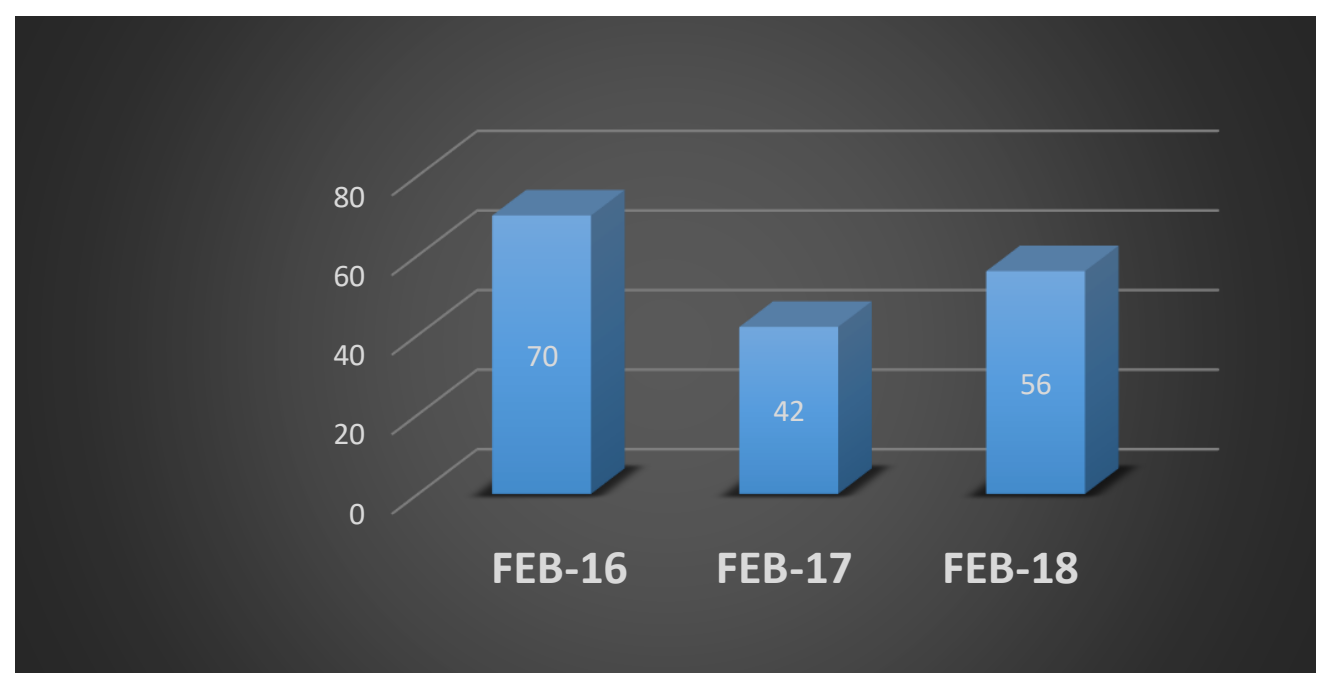

Gambar 5 Perbandingan YOR Impor Setelah Tarif Progresif

\section{KESIMPULAN}

Berdasarkan dari permasalahan yang terdapat dilapangan serta dilengkapi dengan data-data pendukung, maka kesimpulan yang dapat ditarik yaitu:

1. Dwelling Time dan YOR setelah diteliti dengan korelasi memiliki hubungan yang kuat dengan Tarif Progresif nilai signifikasi $0,000<0,05$, dan nilai $r=0,749$ yang artinya mempunyai hubungan korelasi positif sangat kuat. Semakin tinggi dwelling time dan YOR maka tarif progresif harus di naikan

2. Nilai rata-rata dwelling time TPKS berada pada kisaran 6,25 hari pada tahun 2016 dan setelah diberlakukan tarif progresif berada pada kisaran 5,91 hari pada bulan 2017. Hal ini masih kurang dari target yang diinginkan pemerintah yaitu dwelling time harus kurang dari 3 hari.

3. Kebijakan tarif progresif saat ini berdampak pada masih tingginya nilai rata-rata dwelling time dan YOR yang menyebabkan lapangan penumpukan TPKS tetap tinggi dan padat. Selain itu, kebijakan tarif progresif juga menyebabkan biaya logistik tetap mahal.

\section{E. SARAN}

Berdasarkan uraian kesimpulan di atas, maka berikut beberapa saran yang diharapkan dapat bermanfaat bagi perusahaan Terminal Petikemas Semarang maupun pihak lain:

1. TPKS adalah perusahaan bongkar muat harus mampu bekerja sama dengan pihak-pihak lain yang terkait dengan dwelling time agar bisa menekan tingginya dwelling time di lapangan penumpukan.

2. Pemerintahan dan Perusahaan harus lebih tegas lagi terhadap kebijakan dalam pengaturan Standar Operasional Prosedur tentang dwelling time di lapangan dan sudah seharusnya tarif progresif di naikan karena sudah semakin tinggi nilai dwelling time dan YOR nya agar pemilik barang tidak lama menaruh barangnya di lapangan penumpukan TPKS. 


\section{F. DAFTAR PUSTAKA}

Daryanto. Paper Container dan Petikemas. 3 Juli 2018.

https://www.academia.edu/5919356/PAPER_CONTAINER_DAN_PETI_KEMAS (diakses 14 April 2019).

Djoko Wahono.2015. Terminal Petikemas pada pelabuhan internasional pantai kijing di kecamatan sungai kunyit kabupaten Pontianak.

DR.D.A.Lasse. 2012. Manajemen Kepelabuhan. Jakarta

Kramadibrata, Soedjono.2002. Perencanaan Pelabuhan. Institut Bandung.

MERCKX, Filip. 2005. The Issue Of Dwell Time Charges To Optimize Container Terminal Capacity. Jurnal Transportasi dan Ekonomi Regional. Universitas Antwerp Belgia.

Terminal Capacity. Jurnal Transportasi dan Ekonomi Regional. Universitas Antwerp Belgia.

Mulyono, Tri. 2006. Rekayasa Fasilitas Pelabuhan : Dasar-dasar Perencanaan. Program Studi D3Transportasi FT-UNJ. Jakarta

Narindra, R.A.A., Musadieq, M.A., \& Supriono. (2016). Analisis Pengaruh Dwelling Time Terhadap Pendapatan. Jurnal Administrasi Bisnis Vol 41.

Suyono, R.P.Edisi Keempat. 2014. Shipping Pengangkutan Intermodal Ekspor-Impor Melalui Laut. Jakarta: PPM.

Triatmojo, B. 2009. Perencanaan pelabuhan. Yogyakarta: PT sinar cahaya. 